\title{
Phenotypic correlations between body weight and morphometric traits in progenies of mongrel rabbits
}

Udoh, U. H.

\author{
Department of Animal Science, University of Uyo, Nigeria
}

Abstract Corresponding E-mail: utibudy4good@yahoo.com

One of the pre-requisites for genetic improvement is knowledge of genetic parameters for important economic traits $A$ research was conducted with progenies of mongrel rabbits to investigate the phenotypic correlations between body weight and morphometric traits. Rabbits were managed intensively for six months, and fed ad libitum proprietary feed (15\% $\mathrm{CP}$ and $2300 \mathrm{kcal} / \mathrm{kg} \mathrm{ME}$ ), supplemented with forages. Progenies were identified with their dams for data collection. Body weight, and linear body measurements of head and neck circumferences, body, ear and face lengths, hind and forelimbs were analyzed. Measurements were taken once weekly for 10 weeks ( 70 days old). Body weights were taken from 7 days old whereas linear body parameters were taken from 14 days old. Phenotypic correlations between pairs of traits, estimated were positive, showed weak and very strong relationships. Values ranged between 0.455 and 0.986 (1 to 28 days old), 0.288 and 0.841 (29 to 49 days old), 0.174 and 0.781 (50 to 70 days old). The weakest relationship (0.174) existed between neck and head circumferences (50 to 70 days old) whereas the strongest relationship (0.986) existed between body and ear lengths (1 to 28 days old). Higher values (0.539 to 0.917) indicating strong relationships were obtained when estimates were not age specific. Correlated responses in body weight in progenies of mongrel rabbits are expected at varying strengths by selecting and improving any of the linear body parameters. Further breeding researches should investigate phenotypic correlations between body weight and morphometric traits in progenies of mongrel rabbits beyond 70 days of age. Phenotypic correlations involving more parameters should be investigated.

Keywords: Mongrel rabbits, body weight, morphometric traits, phenotypic correlations

\section{Introduction}

The domestic rabbit (Oryctolagus cuniculus) presents favourable biological characteristics as most avian species because the rabbit is characterized by a short generation interval, a high fecundity and prolificacy (Beaumont et al., 2003). Growth traits of rabbits are affected by a number of factors: environment, nutrition, breed, climate, among others. Measuring a progeny's growth and development at different ages gives an insight into the growth and development intensity which varies at certain age structures (Baban et al., 2003). One of the pre-requisites for genetic improvement is knowledge of genetic parameters for important economic traits (Akanno and Ibe, 2006).
Almost all quantitative traits of economic importance are likely to be controlled by a number of genes and each has a relatively minor effect on the trait. On the other hand, each gene may affect not only one trait, but many. Therefore when one trait is selected, other traits may also change genetically. This means that the relationship between economic traits has to be considered when applying selection to improve animal production. Rabbit producers and breeders are interested in the relationships that exist between body weight and linear body traits because this information would tell something about rabbit feed efficiency and production performance (Okoro et al., 2010). However, phenotypic correlations express the relationships between 


\section{Phenotypic correlations between body weight and morphometric traits}

phenotypic values of the animals, which could be seen on the performance of the animals. Therefore phenotypic correlation is of importance in that it provides information regarding the degree to which individual criteria affect each other in the process of selection. According to Ozoje and Mgbere (2002), the final body weight of animals is a reflection of the sum total of the weight of all its component parts. Olutogun et al. (2003) posited that body weight tends to increase as body dimensions increase. Data obtained from such relationships are therefore useful tools for breeders in selecting animals destined for use as breeding stock and also in predicting body weight (Udoh and Udofot, 2016) without resulting to animal slaughter (Isaac et al., 2011).

Phenotypic correlations are important when consideration is given to selection schemes. This is the reason why in this study, these relationships have been analyzed among progenies of mongrel rabbits. The objective of this research was: To determine the relationships between body weight and morphometric characteristics in progenies of mongrel rabbits.

\section{Materials and methods Experimental site}

Experimental site was the Rabbitary Unit, Teaching and Research Farm, Department of Animal Science, University of Uyo, Uyo, Nigeria. Uyo is located between latitude $05^{\circ} 02^{\prime}$ North and longitude $07^{\circ} 56^{\prime}$ East. Uyo has natural day length of $12-13$ hours. The monthly mean minimum temperature ranged from $21.3^{\circ} \mathrm{C}$ to $24.9^{\circ} \mathrm{C}$ and the mean maximum temperature ranged from $28.4^{\circ} \mathrm{C}$ to $34.5^{\circ} \mathrm{C}$. The annual mean rainfall ranged between $2000 \mathrm{~mm}$ and $3000 \mathrm{~mm}$. Relative humidity ranged from $78-93 \%$, courtesy Meteorological Station, Geography Department, University of Uyo, Uyo,
Nigeria. The experiment lasted six (6) months (January to June, 2015).

\section{Management of experimental animals}

Four does and one buck were used for the research. Animals were managed intensively and fed ad libitum with proprietary diet $(25 \% \mathrm{CP}$ and $2300 \mathrm{kcal} / \mathrm{kg}$ ME) in the morning, supplemented with forages in the evening. Clean water was supplied ad libitum. Prophylactic medications were administered against prevalent rabbit infections. Multivitamin preparations were administered in drinking water to boost appetite. The principles of animal care were adhered to strictly throughout the duration of the study.

\section{Mating}

Breeding animals were flushed one week before mating. Data and time of mating were recorded. Does were palpated on the 14 day after mating to confirm conception. Thirty-three kittens generated from the four does were used for the research. Kittens were inspected twice daily and weaned at 42days of age.

\section{Data Collection}

Kittens were systematically ear numbered and identified with their dams for purposes of data collection. Data on the following parameters as described by Salako and Mgbere (2000) were taken once a week on each kitten for 70 days: body weight; body, head and neck circumferences; body, face and ear lengths; fore and hind limbs. Body weights of kittens were taken from 7 days old whereas other linear parameters were taken from 14 days old. Body dimensions were measured with a tailor's measuring tape $(1-100 \mathrm{~cm})$, body weight was assessed with a digital sensitive scale (AHOUS) measured from $0.1 \mathrm{~g}-1.0 \mathrm{~kg}$.

Statistical analysis

All data were analysed with Gen Stat software computer programme. The estimation of phenotypic correlations 
between pairs of traits was done using Completely Randomized Design (CRD).

\section{Results and discussion}

Phenotypic correlations between body weight and morphometric traits at specific age groups in progenies of mongrel rabbits

Correlations between body weight and linear body parameters at specific age groups are presented in Tables 1,2 and 3. At 1 to 28 days old (Table 1), all correlations were positive, ranged between 0.395 and 0.986 , indicating weak to strong relationships. The strongest relationship (0.986) existed between body length and ear length whereas the weakest relationship (0.395) was observed between head circumference and forelimb.

Table 1: Phenotypic correlations between body weight and linear body parameters at 1 to 28 days old

\begin{tabular}{|c|c|c|c|c|c|c|c|c|c|}
\hline Parameter & BW & FL & HL & EL & $\mathrm{HC}$ & BC & BL & FL2 & $\mathbf{N C}$ \\
\hline BW & 1 & & & & & & & & \\
\hline FL & 0.766 & 1 & & & & & & & \\
\hline HL & 0.675 & 0.937 & 1 & & & & & & \\
\hline EL & 0.777 & 0.804 & 0.647 & 1 & & & & & \\
\hline $\mathrm{HC}$ & 0.587 & 0.395 & 0.860 & 0.701 & 1 & & & & \\
\hline $\mathrm{BC}$ & 0.886 & 0.866 & 0.732 & 0.905 & 0.705 & 1 & & & \\
\hline BL & 0.731 & 0.729 & 0.578 & 0.986 & 0.677 & 0.836 & 1 & & \\
\hline FL2 & 0.749 & 0.704 & 0.533 & 0.985 & 0.744 & 0.879 & 0.978 & 1 & \\
\hline $\mathrm{NC}$ & 0.766 & 0.810 & 0.755 & 0.827 & 0.455 & 0.900 & 0.748 & 0.821 & 1 \\
\hline
\end{tabular}

At 29 to 49 days old (Table 2), all correlations were positive. Okoro et al. (2010) also reported positive phenotypic correlation estimates within the age range. This means that as any one linear body measurement or body weight is increasing, a corresponding increase in expressed in the other. In the present study, correlation estimates within 29 and 49 days age group ranged between 0.232 and 0.741 , indicating weak and strong relationships. The strongest relationship (0.741) existed between body weight and forelimb, whereas the weakest relationship (0.232) was observed between neck and head circumferences.

Table 2: Phenotypic correlations between body weight and linear body parameters at 29 to 49 days old

\begin{tabular}{|c|c|c|c|c|c|c|c|c|c|}
\hline Parameter & BW & FL & HL & EL & $\mathrm{HC}$ & $\mathrm{BC}$ & BL & FL2 & $\mathrm{NC}$ \\
\hline BW & 1 & & & & & & & & \\
\hline FL & $0.741(* *)$ & 1 & & & & & & & \\
\hline HL & $0.573(* *)$ & $0.574(* *)$ & 1 & & & & & & \\
\hline EL & $0.592(* *)$ & $0.507(* *)$ & $0.507(* *)$ & 1 & & & & & \\
\hline $\mathrm{HC}$ & $0.492(* *)$ & $0.342(* *)$ & $0.576(* *)$ & $0.389(* *)$ & 1 & & & & \\
\hline $\mathrm{BC}$ & $0.736(* *)$ & $0.841(* *)$ & $0.639(* *)$ & $0.396(* *)$ & $0.471(* *)$ & 1 & & & \\
\hline $\mathrm{BL}$ & $0.565(* *)$ & $0.670(* *)$ & $0.726(* *)$ & $0.492(* *)$ & $0.439(* *)$ & $0.714(* *)$ & 1 & & \\
\hline FL2 & $0.595(* *)$ & $0.360(* *)$ & $0.311(* *)$ & $0.527(* *)$ & $0.469(* *)$ & $0.306(* *)$ & $0.321(* *)$ & 1 & \\
\hline $\mathrm{NC}$ & $0.569(* *)$ & $0.471(* *)$ & $0.368(* *)$ & $0.288\left(^{*}\right)$ & $0.232(*)$ & $0.520(* *)$ & $0.498(* *)$ & $0.470(* *)$ & 1 \\
\hline
\end{tabular}




\section{Phenotypic correlations between body weight and morphometric traits}

At 50 to 70 days old (Table 3), correlations were positive, ranged between 0.174 and 0.781 , indicating very weak and strong relationships. The strongest relationship (0.781) existed between body weight and body length, whereas the weakest relationship (0.174) was observed between neck circumference and ear length. Weakest relationships were observed with ear length. In all age groups, relationships with body length were either strong or very strong. More relationships became weak with age.

Phenotypic correlations between body weight and morphometric traits in progenies of mongrel rabbits without

\section{recourse to age groups}

When phenotypic correlations between body weight and morphometric traits in progenies of mongrel rabbits were considered without recourse to age groups (Table 4), all correlations were positive. Higher values of correlations (0.539 to 0.917) indicating stronger relationships than those at specific age groups were obtained. The strength of those relationships was strong or very strong. The weakest relationship (0.539) was obtained between neck and head circumferences, whereas strongest relationships were obtained with body weight. These results were in agreement with the results obtained by Obike et al. (2010) and Oke et al. (2012).

Table 3: Phenotypic correlations between body weight and linear body paramet ers at 50 to 50 day old

\begin{tabular}{|c|c|c|c|c|c|c|c|c|c|}
\hline Parameter & BW & FL & HL & EL & HC & BC & BL & FL2 & NC \\
\hline BW & 1 & & & & & & & & \\
\hline FL & $0.746(* *)$ & 1 & & & & & & & \\
\hline HL & $0.747(* *)$ & $0.630(* *)$ & 1 & & & & & & \\
\hline EL & $0.405(* *)$ & $0.435(* *)$ & $0.433(* *)$ & 1 & & & & & \\
\hline $\mathrm{HC}$ & $0.734(* *)$ & $0.695(* *)$ & $0.686(* *)$ & $0.414(* *)$ & 1 & & & & \\
\hline $\mathrm{BC}$ & $0.732(* *)$ & $0.572(* *)$ & $0.538(* *)$ & $0.296(* *)$ & $0.729(* *)$ & 1 & & & \\
\hline BL & $0.781(* *)$ & $0.656(* *)$ & $0.619(* *)$ & $0.387(* *)$ & $0.714(* *)$ & $0.758(* *)$ & 1 & & \\
\hline FL2 & $0.467(* *)$ & $0.370(* *)$ & $0.524(* *)$ & $0.222(*)$ & $0.526(* *)$ & $0.328(* *)$ & $0.319(* *)$ & 1 & \\
\hline $\mathrm{NC}$ & $0.472(* *)$ & $0.351(* *)$ & $0.304(* *)$ & $0.174(*)$ & $0.386(* *)$ & $0.326(* *)$ & $0.268(*)$ & $0.376(* *)$ & 1 \\
\hline
\end{tabular}

Table 4: Phenotypic correlations between body weight and linear body parameters without recourse to age group

\begin{tabular}{|c|c|c|c|c|c|c|c|c|c|}
\hline Parameter & BW & FL & HL & EL & $\mathrm{HC}$ & $\mathrm{BC}$ & BL & FL2 & $\mathrm{NC}$ \\
\hline $\mathrm{BW}$ & 1 & & & & & & & & \\
\hline FL & 0.917 & 1 & & & & & & & \\
\hline HL & 0.893 & 0.886 & 1 & & & & & & \\
\hline EL & 0.795 & 0.812 & 0.778 & 1 & & & & & \\
\hline $\mathrm{HC}$ & 0.724 & 0.655 & 0.708 & 0.616 & 1 & & & & \\
\hline $\mathrm{BC}$ & 0.887 & 0.884 & 0.833 & 0.723 & 0.730 & 1 & & & \\
\hline BL & 0.797 & 0.812 & 0.791 & 0.745 & 0.705 & 0.835 & 1 & & \\
\hline FL2 & 0.659 & 0.644 & 0.608 & 0.667 & 0.632 & 0.618 & 0.726 & 1 & \\
\hline $\mathrm{NC}$ & 0.738 & 0.739 & 0.680 & 0.642 & 0.539 & 0.720 & 0.717 & 0.707 & 1 \\
\hline
\end{tabular}

Phenotypic correlations among traits may be defined as the gross observed correlations that include genetic and environmental factors. Environmental factors encompass all the physical conditions in association with the animals. Therefore the phenotypic correlations observed in this study among traits are 
important because they directly indicate the size of selection differential expected in mongrel rabbits if selection is done. Very high and high positive phenotypic correlations observed between some traits in this study indicate where large correlated responses are expected with selection. The medium and weak phenotypic correlations indicate where little correlated responses are expected with selection, because of the weak relationships. The results therefore revealed age groups at which selection should not be carried out so as to derive maximum correlated responses. Generally, correlated responses in body weight in progenies of mongrel rabbits are expected at varying strengths by selecting and improving any of the linear parameters.

\section{Conclusion and recommendation}

The study showed that phenotypic correlations between body weight and linear body measurements in progenies of mongrel rabbits were positive, ranging from weak to very strong relationships. Higher values indicating stronger relationships were obtained when estimates were not age specific. Correlated responses in body weight in progenies of mongrel rabbits are expected at varying strengths by selecting and improving any of the linear body parameters.

Further breeding researches should investigate phenotypic correlations between body weight and morphometric traits in progenies of mongrel rabbits beyond 70 days of age. Phenotypic correlations involving more parameters should be investigated.

\section{References}

Akanno, E. C. and Ibe, S. N. 2006. Prediction of body weight of the domestic rabbits at different stages of growth using linear body measurements. Nigerian Journal of Animal Production 33(1):3 - 8 .

Baban, M., Rastija, T., Knezevic, I., Mandic, I., Sencic, D., Antunovic, Z., Mijic, P. and Curik, I. 2003. Phenotypic correlations among morphometric traits measured during the growth of the Lipizzan horse. Agriculture Consepectus Scientitficus 64(4):239-243.

Beaumont, C., Chapuis, H. and Roussot, O. 2003. Genetique et selection avicoles. Evolution des methods et de caracteres. INRA Prod. Anim. 17(1):35-43.

Isaac, L. J., Udoh, U. H., Usoro, O. O., Ekanem, E. and Williams, M. E. 2011. Relationship between body weight and linear body measurements in different breeds of rabbits. Proceedings of the $36^{\text {th }}$ Annual Conference of the Nigerian So c i e ty for A n i m a 1 Production. Abuja, Nigeria. Pp.1012.

Obike, O. M., Ibe, S. N. and Oke, U. K. 2010. Estimation of pre - and post weaning body weight of rabbits in a humid tropical environment using linear body measurements. Journal of Agriculture and Environmental Science 9(4):440 - 444.

Oke, U. K., Herbert, U., Nwichi, C., Onyiro, O. M. and Okocha, C. N. 2010. Effect of breed of sire on growth performance of crossbred rabbits in a humid tropical environment. Proceedings of $35^{\text {th }}$ Annual Conference, Nigerian Society for Animal Production. Ibadan, Nigeria. Pp. 15-17.

Okoro, V. M., Ezeokeke, C. T. and Chukwuchum, U. E. 2010. Phenotypic Correlations of body weight and linear body 
measurements in Chinchilla rabbits (Oryctolagus cunniculus). Journal of Agricultural Biotechnology and Sustainable Development 2: 27-29.

Olutogun, O., Abdullah, A. R., Raji, A. O., Adetoro, P. A. and Adeyemi, A. 2003. Body conformation characteristics of White Fulani and Gudali (Zebu) cattle breeds of Nigeria. Proceedings of $28^{\text {th }}$ Annual Conference of Nigerian Society for Animal Production. Ibadan, Nigeria. Pp. 129-132.

Ozoje, M. O. and Mgbere, O. O. 2002. Coat pigmentation effects in West African Dwarf goats: live weights and body dimensions. Nigerian Journal of Animal Production 29:5 -10 .
Salako, A. E. and Mgbere, O. O. 2002. Application of multifactorial discriminant analysis in the morphometric structural differentiation of West African dwarf and yankassa sheep in southwest Nigeria. Nigerian Journal of Animal Production 29:163 - 167.

Udoh, U. H. and Udofot, M. M. 2016. Pattern of early growth traits and predictions in progenies of mongrel rabbits. British Journal of Applied Science and Technology 17(16): 1 8.

Received: $11^{\text {th }}$ March, 2017

Accepted: $27^{\text {th }}$ July, 2017 